\title{
RETRACTED ARTICLE: Isolation, purification and partial characterization of a lectin protein from the seeds of green seeded chickpea PUSA hara chana (Cicer arietinum L.)
}

Prasanta K. Dash

Received: 10 December 2012 / Accepted: 18 March 2013 / Published online: 13 April 2013

(C) Society for Plant Biochemistry and Biotechnology 2013

This article has been retracted by the Editor-in-Chief of Journal of Plant Biochemistry and Biotechnology due to plagiarism.

This article has been retracted by the Editor-in-Chief of Journal of Plant Biochemistry and Biotechnology due to plagiarism.

P. K. Dash $(\triangle)$

LBS Building, Lab No D 20, National Research Centre on Plant

Biotechnology, Indian Council of Agricultural Research,

New Delhi 110012, India

e-mail: prasanta01@yahoo.com 